\title{
Large-scale circulation and flushing characteristics of the North Sea under various climate forcings
}

\author{
Meinte Blaas*, David Kerkhoven, Huib E. de Swart \\ Institute for Marine \& Atmospheric Research Utrecht (IMAU), Utrecht University, PO Box 80005, Utrecht 3508TA, \\ The Netherlands
}

\begin{abstract}
With the aid of a numerical model it is shown that, in addition to the residual effects of tides and winds, the meridional density distribution in the North-East Atlantic Ocean has a significant effect on the large-scale, residual circulation in the North Sea. This effect is due to the fact that the currents along the continental slope, which are mainly forced by density gradients and tides, intrude into the deeper parts of the shelf sea and, as a consequence, oppose or enhance the wind-driven circulation. From dispersion-model experiments it is demonstrated that the interplay of the tide, ocean density, and winds results in efficient flushing of the basin if their effects coincide. However, the residual circulation may break up into closed cells on the shelf if forcings counteract. In that case, efficient renewal of material is inhibited. The characteristics of the dispersion of material in the shelf sea are quantified by computing the spatial distributions of residence times. In addition, basin-wide flushing characteristics are typified by calculating turn-over and flushing time scales. The ratio of these time scales is used as a measure for the relative retention strength of material within the basin by closed circulation cells.
\end{abstract}

KEY WORDS: North Sea $\cdot$ Residual circulation $\cdot$ Residence time $\cdot$ Flushing time $\cdot$ Turn-over time

\section{INTRODUCTION}

Water motion in shelf seas, such as the North Sea, is driven by tides, winds, and density gradients, which vary on a broad range of spatial and temporal scales. Both observational and modeling studies concerning the circulation of the North Sea (e.g. various contributions in Sündermann 1994) indicate that these forcings, despite their variability, produce a significant longterm mean (i.e. residual) circulation of water masses. In addition, these studies show that the long-term and large-scale characteristics of spreading and transport of dissolved and suspended material (i.e. flushing characteristics) are largely determined by this residual circulation, whereas the variability of the circulation can be regarded as a mixing effect. Both for scientific and practical reasons (e.g. fisheries, ecology, pollution) it is important to assess the sensitivity of the large-

*E-mail: blaas@phys.uu.nl scale circulation and flushing characteristics to changes in the forcing conditions.

Forcing conditions for the North Sea have been different in the past, as has for example been shown by analysis of proxy data and modeling studies concerning the geological past of the North Sea circulation (Hass 1996). Moreover, anthropogenic climate change studies indicate that the forcing of the shelf sea circulation by the atmosphere and adjacent ocean may possibly differ in future as well (e.g. Kattenberg et al. 1995). In this respect, sensitivity studies have already been carried out in which the consequences of atmospheric climate changes (in winds and/or precipitation) have been investigated (e.g. Backhaus 1989, 1996, Pohlmann \& Puls 1994). These studies have led to the idea that the present-day climate conditions are the most favorable for the renewal of water masses in the North Sea.

In this paper it will be demonstrated that, apart from the atmospheric conditions, the meridional density gradient in the NE Atlantic Ocean also influences the 
residual circulation in the North Sea and, moreover, that it influences the flushing characteristics on the shelf as well. The connection between the NE Atlantic density structure and the shelf circulation is made by the persistent poleward current that is flowing at the top of the West-European continental slope (e.g. Huthnance 1986, Pingree et al. 1999). This current is mainly forced by the meridional density gradient on the NE Atlantic and is following the topography such that it partly intrudes into the deep parts of the North Sea (see also Pingree \& Le Cann 1989, and Blaas et al. 2000).

The meridional density gradient in the NE Atlantic is related to the wind- and density-driven circulation of the Atlantic Ocean. The thermohaline circulation (THC) in particular is controlled by, and itself determines, the increase of surface-water density towards the sub-arctic regions of the Atlantic Ocean (e.g. Broecker 1991). Analyses of ice-core data have related climatic changes in the geological past to changes in the THC (e.g. Stocker \& Mysak 1992, Dansgaard et al. 1993, Broecker 1997) and reconstructions of North

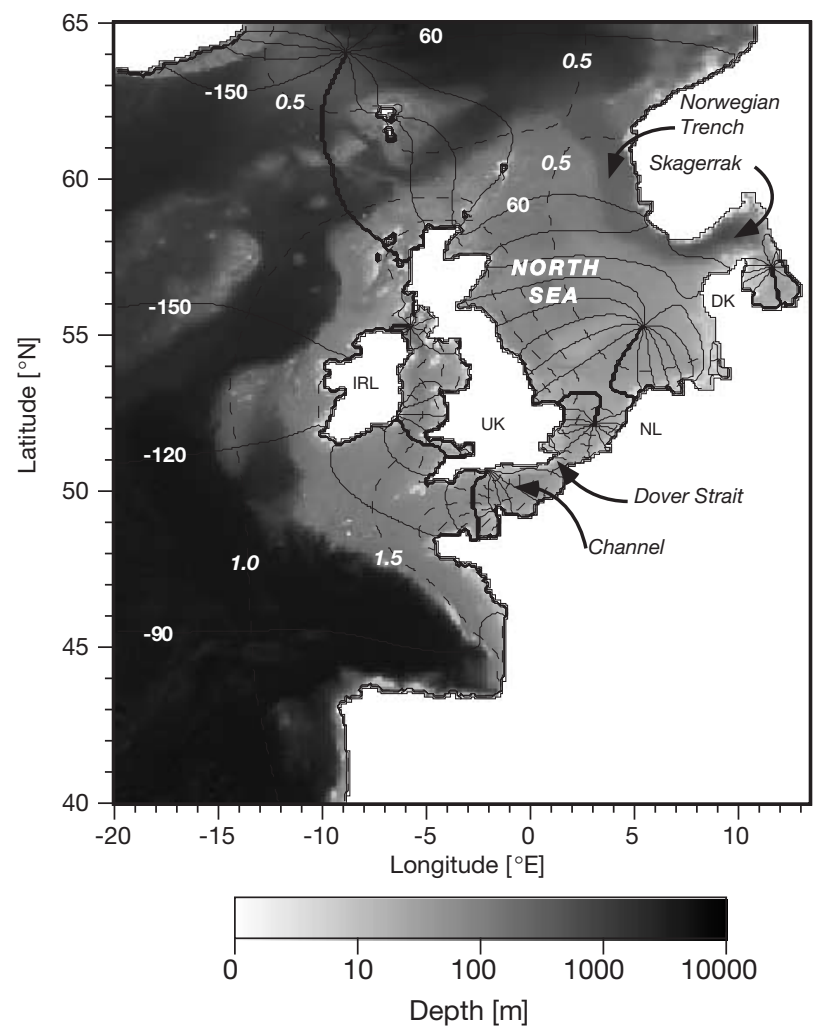

Fig. 1. Bottom topography of the North Sea and adjacent Atlantic Ocean in the domain of the hydrodynamic model. Contour lines are amplitude (dashed, interval $0.5 \mathrm{~m}$, italic labels in meters) and phase (solid, bold contour $180^{\circ}$, interval $30^{\circ}$, labels in degrees) of semidiurnal tide as computed by the hydrodynamic model. Text in italics indicates geographic features mentioned
Atlantic sea surface temperature and salinity suggest that, for example during the last glacial maximum (1.8 $\times 10^{4} \mathrm{yr} \mathrm{BP}$ ), sea surface conditions were substantially different from the present-day (Duplessy et al. 1991).

Climate modeling studies suggest that severe changes in the THC may occur again in the future if atmospheric $\mathrm{CO}_{2}$ concentrations exceed critical levels. Due to atmospheric warming, the upper layers of the North East Atlantic may become less saline than nowadays, which will inhibit the formation of deep water and thus hinder the thermohaline overturning (e.g. Manabe \& Stouffer 1994, Schiller et al. 1997, Schmittner \& Stocker 1999). During these different climate conditions not only will the atmospheric circulation have been or be different, but also the density-driven slope current may have been or be weaker or even reversed. These aspects have motivated the sensitivity experiments in this paper.

The organization of this paper is as follows. In section 2, a numerical hydrodynamic model is presented with which the circulation in the North Sea and adjacent ocean due to tides, stationary winds and ocean density gradients is calculated. The consequences of the resulting circulation patterns for large-scale mixing and the flushing of water masses in the North Sea are quantified and analyzed from experiments with a tracer transport model in section 3. The final section contains a brief discussion and conclusions.

\section{CIRCULATION MODEL}

\subsection{Model description}

A numerical hydrodynamic model, based on the 'Hamburg Shelf-Ocean Model' (HAMSOM, Backhaus 1983, 1985), is applied to the domain shown in Fig. 1. It solves the shallow-water equations on a spherical grid of $5^{\prime}$ lat. $\times 7.5^{\prime}$ lon. $\left(\sim 9 \times 9 \mathrm{~km}\right.$ at $\left.50^{\circ} \mathrm{N}\right)$ on 2 vertical levels, 1 from sea level down to $700 \mathrm{~m}$ and 1 from $700 \mathrm{~m}$ to the bottom. This vertical discretisation is used to give a first order approximation of the vertical structure of the deep sea, where a permanent thermocline is present at $\sim 700 \mathrm{~m}$ depth. At the open boundaries the model is forced by a representative semi-diurnal tide and a time-independent mean sea level associated with the ocean-density structure. The time step $\Delta t=20 \mathrm{~min}$ is sufficiently small to describe the major overtides that are internally generated due to nonlinearities in the water motion.

Two scenarios have been set up to approximate both the present-day climatological mean conditions and possible extreme 'greenhouse climate' conditions. For the former scenario, annual-mean salinity and temperature data have been adopted from Levitus et al. (1994) 
and Levitus \& Boyer (1994). The latter scenario has been inferred from GCM experiments by Manabe \& Stouffer (1994), in which the global thermohaline circulation has ceased due to increase of atmospheric $\mathrm{CO}_{2}$ up to 4 times present-day concentration levels.

Salinity and temperature have been assumed to be zonally uniform and linearly distributed between the northern and southern model boundaries. In all model runs, density is treated diagnostically in both layers, hence the contribution of density to the pressure gradients is prescribed and the permanent thermocline is kept fixed. The characteristics of the upper layer as well as the density difference between the northern and southern boundary corresponding to the scenarios are listed in Table 1. The lower layer characteristics have been kept the same for both experiments: $T=$ $4.0^{\circ} \mathrm{C}$ and $S=34.8 \mathrm{ppt}$, such that the column was stably stratified.

The wind scenarios have been set up as first order approximations of different extremes: uniform SW winds and NE winds. These directions have been chosen because SW winds are a reasonable approximation of the present-day climatological conditions over the North Sea (cf., Hellerman \& Rosenstein 1983) and NE winds form the most extreme opposite conditions. Moreover, from idealised studies by Furnes (1980) it can be concluded that the wind-driven circulation is most sensitive to wind directions parallel to the large-scale depth gradients (i.e. from the Southern Bight to the Norwegian Trench). For each of the 2 different directions, 2 different strengths have been chosen. The wind scenarios are listed in Table 2. In sections 3.2.1 and 3.2.2 an additional experiment is discussed with a slightly stronger SW wind (i.e. $W=1.6, \Delta P=0$ ) to compare the dispersion model results with those of Prandle (1984).

\subsection{Model results}

A total of 15 experiments has been carried out in which stationary residual circulation patterns have been computed. For each of the 5 wind-stress scenarios the density-forcing has been varied, such that the relative influence of both forcings could be studied.

Analysis of transport data, some of which are shown in Fig. 2, shows that the model response to wind stress is largely linear for all density gradients: the magnitude of the transport due to winds (i.e. after subtraction of the tide-driven transport as computed by the model with tidal forcing only) is linearly proportional to wind stress and, for opposite wind direction, the winddriven circulation is opposite and practically equal in magnitude. This result supports the approach by Prandle (1984) who had set up a linear model for the windand tide-driven residual circulation.
Table 1. Scenarios for density distribution of upper ocean layer; 'north' and 'south' refer to characteristics at northernmost and southernmost open boundary of model domain respectively. Scenario $\Delta \mathrm{P}=+1$, present-day situation (Levitus \& Boyer 1994, Levitus et al. 1994); $\Delta \mathrm{P}=-1$, scenario in which thermohaline circulation in North Atlantic has ceased (ad. from Manabe \& Stouffer 1994)

\begin{tabular}{|lccccc|}
\hline & \multicolumn{2}{c}{ SST $\left[{ }^{\circ} \mathrm{C}\right]$} & \multicolumn{2}{c|}{ SSS [ppt] } & $\Delta \rho\left[\mathrm{kg} \mathrm{m}^{-3}\right]$ \\
& North South & North South & North - South \\
\hline$\Delta P=+1$ & 6.0 & 13.8 & 34.96 & 35.8 & +0.7 \\
$\Delta P=0$ & - & - & - & - & - \\
$\Delta P=-1$ & 10.0 & 15.8 & 33.0 & 35.8 & -0.6 \\
\hline
\end{tabular}

Table 2. Wind scenarios as applied to hydrodynamic model. In density-forcing investigations (see also Table 1), 2 wind speeds have been chosen for each of the 2 opposite wind directions

\begin{tabular}{|rlc|}
\hline$W$ & $|\tau|[\mathrm{Pa}]$ & Direction \\
\hline 4 & 0.18 & $\mathrm{SW}$ \\
1 & 0.042 & $\mathrm{SW}$ \\
0 & 0.00 & - \\
-1 & 0.042 & $\mathrm{NE}$ \\
-4 & 0.18 & $\mathrm{NE}$ \\
\hline
\end{tabular}

However, in the Skagerrak, the Norwegian Trench and close to the coasts, the wind-driven response is nonlinear. These are areas where vorticity in the mean flow is strongest and tidal rectification can be affected by the presence of the (wind-driven) mean flow, as has been pointed out by Blaas et al. (2000).

Also, the differences in the residual circulation between $\Delta P=0$ and $\Delta P=+1$ are larger than between $\Delta P=-1$ and $\Delta P=0$ for all wind stresses. This asymmetry might be due to different strengths of the slope current when it enters the basin, flowing either north (present-day situation) or south (climate change scenario).

\section{DISPERSION MODEL}

\subsection{Model description}

When changing forcing conditions affect the residual circulation in the North Sea, they will also influence the long-term transport and distribution of water masses on a time-scale of several years. To assess this for the various scenarios discussed previously, a passive tracer transport model has been set up for the shelf sea. It solves the depth-integrated, tide-averaged advection-diffusion equation for tracer concentration, which in cartesian coordinates reads: 
$\frac{\partial}{\partial t}(H C)+\frac{\partial}{\partial x}(U c)+\frac{\partial}{\partial y}(V C)-\frac{\partial}{\partial x}\left(H K_{x} \frac{\partial c}{\partial x}\right)-\frac{\partial}{\partial y}\left(H K_{y} \frac{\partial c}{\partial y}\right)=0$

Here $c(x, y, t)$ is the depth-averaged and tide-averaged tracer concentration (still depending on time scales larger than the tidal period), $H$ is the tide-averaged water depth, $U$ and $V$ are the residual horizontal transport components $\left(\mathrm{m}^{2} \mathrm{~s}^{-1}\right)$ and $K_{x}$ and $K_{y}$ are the coefficients of tide-averaged dispersion. The main source of dispersion is thought to be due to the shortterm variability of the currents related to winds and tide. Here, a parameterisation of $K_{X}$ and $K_{Y}$ has been chosen in terms of the tidal currents partly because the current variations due to winds are unknown under changing climate conditions and partly because tidal
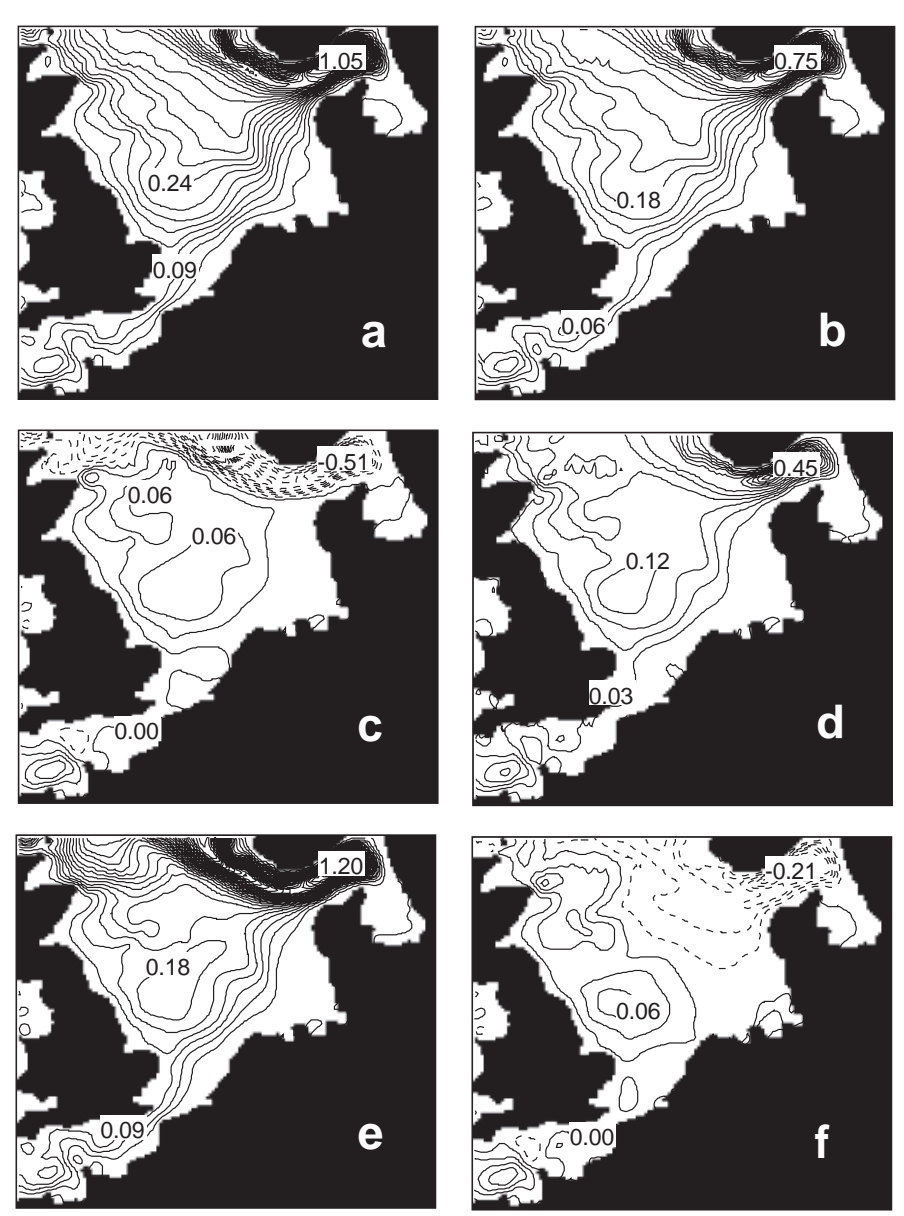

Fig. 2. Stationary volume transport as computed by the numerical model forced by stationary uniform winds and ocean density gradients (units in Sverdrup). (a) an experiment carried out in addition to the 15 standard experiments for comparison with results by Prandle (1984), $\Delta P=0, W=1.6$; (b) $\Delta P=0, W=+1$; (c) $\Delta P=-1, W=0$; (d) $\Delta P$ $=0, W=0 ;(\mathrm{e}) \Delta P=+1, W=0$; (f) $\Delta P=0, W=-1$. Positive (negative) stream function values, indicated by solid (dashed) contours, correspond to cyclonic (anticyclonic) circulation. Contour intervals, $0.03 \mathrm{~Sv}\left(1 \mathrm{~Sv}=10^{6} \mathrm{~m}^{3} \mathrm{~s}^{-1}\right)$ currents prevail over wind-driven currents most of the time and in most locations.

$$
\left(\begin{array}{l}
K_{X} \\
K_{Y}
\end{array}\right)=\alpha \frac{2 \pi}{\sigma}\left(\begin{array}{l}
u_{0} \\
v_{0}
\end{array}\right) \sqrt{u_{0}^{2}+v_{0}^{2}}
$$

Here $\sigma=1.4 \times 10^{-4} \mathrm{~s}^{-1}$ is the semi-diurnal tidal frequency, $u_{0}$ and $v_{0}$ are the horizontal tidal velocity amplitudes and $\alpha$ a parameter of proportionality. The value of $\alpha$ has been varied to test the sensitivity of the results to the magnitude of the dispersion coefficients. The results discussed below do not depend sensitively on the exact magnitude of $\alpha$. A value of $\alpha=0.022$ was chosen such that the model is consistent with that used by Prandle (1984), who has compared his dispersion model to observations of the large-scale spreading of ${ }^{137} \mathrm{Cs}$ in the West European shelf seas. The spatial grid resolution (i.e. spherical, $20^{\prime}$ lat. $\times 30^{\prime}$ lon.) is also equal to Prandle's model, such that direct comparison with the latter can be made.

As discussed in the previous section, the stationary transport data $(U, V$ in Eq. 1) serve as input for 15 scenarios in the tracer dispersion model for which the distribution of substance in space and time can be calculated. Validation of the dispersion model has been done by calculation of the relative contribution of the inflow regions (i.e. waters from northern inflow regions and Channel waters) to the steady-state water mass distribution over the model grid. The results could be reasonably well compared to similar quantities derived from observations of radionuclides and salinity in the summer of 1988 (Bailly du Bois et al. 1993). For further detail on these validation studies see Kerkhoven (2000). A validation in terms of time-scales is shown in the next section, where the spatial distribution of 'age' (i.e. travel time) of material is discussed.

\subsection{Model results}

To give a concise quantification of flushing and dispersion characteristics within the North Sea for each scenario, characteristic time scales have been calculated with the aid of the dispersion model. In each subsection a brief definition of the relevant time-scales is given. A more elaborate discussion on these time scales can be found in Bolin \& Rodhe (1973), Zimmerman (1976) and Prandle (1984).

\subsubsection{Age distribution}

To provide a comparison with the computations of age by Prandle (1984) and the observations of 


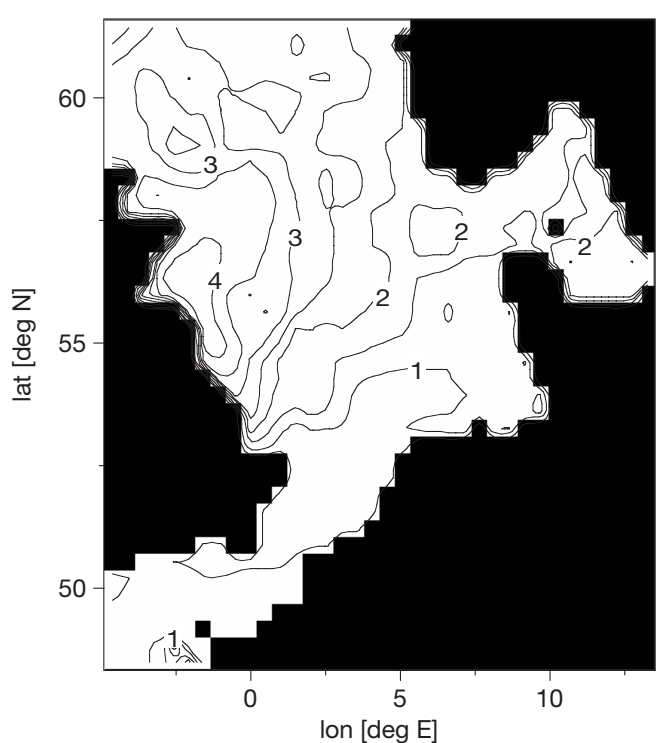

Fig. 3. Age distribution (contour interval $0.5 \mathrm{yr}$ ) as computed with the tide-averaged dispersion model for forcing used by Prandle (1984) $(W=1.6, \Delta P=0)$. The corresponding circulation pattern is shown in Fig. 2a

Kautsky (1973), an example of the calculation of age is given here. The age of a certain location is defined as the time needed for dissolved substance to be transported from a well-defined source location (in this case, the Cap de la Hague nuclear fuel reprocessing plant) to the location under consideration. Under representative present-day forcing-conditions, as have also been applied by Prandle (1984), these results compare fairly well to travel times for ${ }^{137} \mathrm{Cs}$ reported from observations by Kautsky (1973) and to computations by Prandle (1984). These results give satisfactory confidence in the skill of the dispersion model.

\subsubsection{Residence time}

Residence time is the time scale that is indicative for the time needed to transport substance from a certain initial position to the model boundaries. It is computed as the time needed for the mass of material, initially introduced at the location where the residence time is defined, to be removed from the basin as a whole.

From Fig. $4 a, b$ the influence of wind-forcing on residence time can be seen. The former is calculated with tidal forcing only ( $W=0, \Delta P=0$ ) and the latter with tidal and wind-forcing $(W=1.6, \Delta P=0)$. The results of this scenario agree with the residence times obtained by Prandle (1984) for the same wind field: residence times of $\sim 100 \mathrm{~d}$ in the Norwegian Trench, $\sim 2 \mathrm{yr}$ in the central and southern North Sea and up to 4 yr off Scotland. The circulation pattern is reflected in the distrib- ution of residence times; the tracer is mainly advected along the streamlines. Consequently, residence in the basin becomes shorter the closer the initial position of tracer release to the outflow areas, or the stronger the flow.

It can be seen that the wind reduces the residence times by a factor of 5 in the central North Sea and up to a factor of 10 north of the Norwegian Trench. Along the east coast of Britain and along the European coast the reduction is a factor of about 2 . In the Channel the reduction is $<30 \%$. These results point out the strong influence of wind-forcing on the dispersion of water mass on the shelf.

The effect of ocean density can be derived from comparison in Fig. 4a,c,d. The addition of present-day density-forcing strongly changes the residence time pattern in comparison with solely tide-driven circulation. Differences are largest in the northern North Sea (decrease by a factor of 10) and in the Kattegat east of Denmark (increase in residence time up to a factor of 2). In the central North Sea a reduction of residence
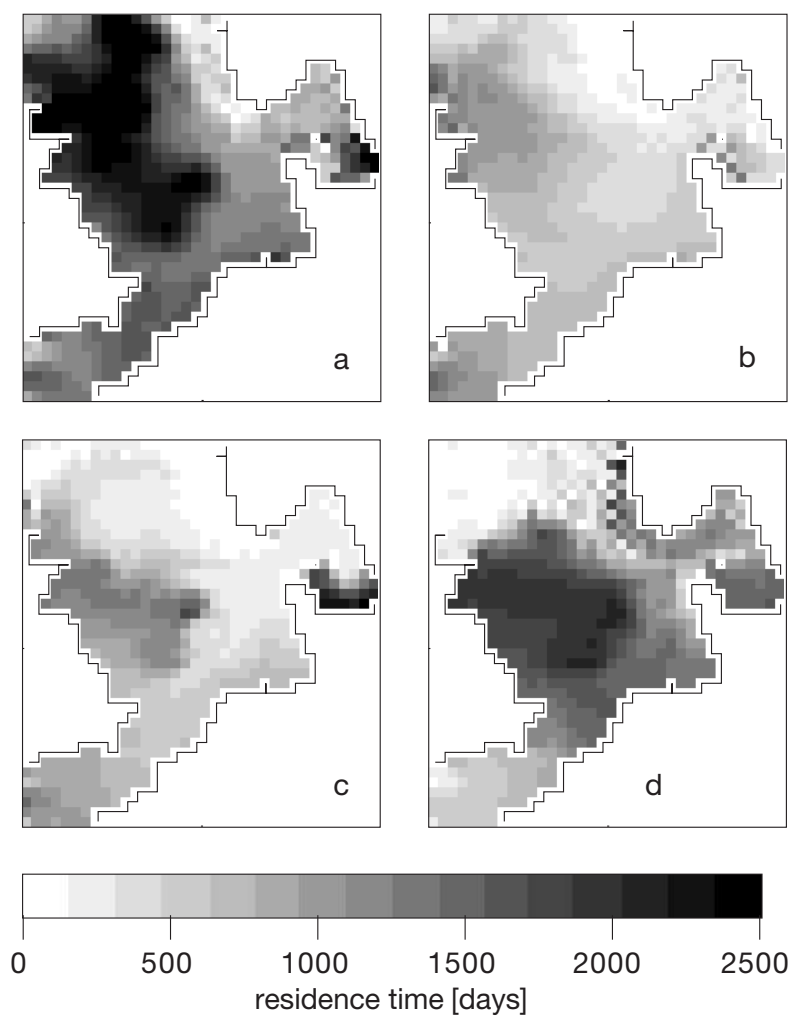

Fig. 4. Residence time (d) as computed with tide-averaged dispersion model for 4 stationary circulation patterns driven by: (a) tides only ( $W=0, \Delta P=0$ ); (b) tides and steady $\mathrm{SW}$ winds, no density-forcing $(W=1.6, \Delta P=0)$; (c) tides and ocean density corresponding to present-day conditions, no winds $(\Delta P=1, W=0)$; (d) tides and reversed ocean density gradient, no winds $(\Delta P=-1, W=0)$. The corresponding circulation patterns are shown in Fig. 2d,a,e,c respectively 
time with a factor of 2 occurs. If the opposite densityforcing is applied, the residence time increases in most of the domain with respect to present-day forcing. An exception is the deep shelf northeast of Scotland where a reduction is found since the inflow area has been turned into an outflow area. The pattern in Fig. 4d clearly shows that, due to the reversal of circulation in the Norwegian Trench, the lower residence times are now found on the western flank of the trench, whereas in all the previous graphs a minimum was located near the Norwegian coast. Another conspicuous feature is the local maximum in the central North Sea that has gained relative strength; this maximum is associated with the dipole-like structure (see also Fig. 2e) of the circulation: due to the cyclonic circulation on the shallow shelf and the anti-cyclonic circulation in the Norwegian Trench and deeper shelf, the waters in the central North Sea have become more isolated from the outflow boundaries.

\subsubsection{Global time scales}

In the following the focus is on global time scales that describe basin-wide characteristics: turn over time $\left(\tau_{\mathrm{e}}\right)$ and flushing time $\left(\tau_{f}\right)$. The former is defined as the $e$-folding time-scale of replacement of material within the model domain by material from outside the domain; the latter is defined as the ratio of the domain's volume $V$ and inward (or outward) volume flux $Q$ over the open boundaries ( $V$ and $Q$ are both considered to be time-independent):

$$
\tau_{f}=\frac{V}{Q}
$$

Note that $\tau_{f}=\tau_{\mathrm{e}}$ if the tracer flux across the boundary is purely advective and equals $Q$ times the basin-mean concentration $\hat{C}$, i.e. if the rate of change of basinaveraged concentration obeys the following:

$$
V \frac{\partial \hat{C}}{\partial t}=-Q \hat{C}
$$

This relation is valid for a perfectly well-mixed flow system dominated by advection at the boundaries. Usually, however, $\tau_{\mathrm{e}}>\tau_{f}$, which indicates that the tracer concentration within the area under investigation differs from a homogeneous distribution. The ratio $R_{\mathrm{e} f}=\tau_{\mathrm{e}} / \tau_{f}$ thus is a measure for the inhomogeneity, or the 'relative strength of retention' by closed circulation cells within the basin that causes this inhomogeneity.

In Fig. 5, the turnover time is shown as a function of normalized wind stress for different ocean-density forcings. It appears that for $\Delta P=0$, increasing southwesterly (i.e. northeastward, positive) wind stresses results in reduction of $\tau_{\mathrm{e}}$, an enhancement of the water mass renewal. The response is nonlinear: increasing the wind stress from $W=0$ to $W=1$ halves $\tau_{\mathrm{e}}$ a second reduction by a factor of 2 is found after a 4 -fold increase in wind stress. In the discussion of the transport data it has already been pointed out that positive wind stresses and tides both drive cyclonic circulation on the shelf. On the other hand, weak northeasterly winds, $W=-1$, increase turnover time, since then the wind-driven anticyclonic circulation opposes the tideinduced pattern. Nonetheless, for strong northeasterly winds the wind-driven circulation is strong enough to overcome the tide-driven component, resulting in a reduction of $\tau_{\mathrm{e}}$.

A similar discussion applies to the cases including ocean forcing: $\Delta P=+1$ and $\Delta P=-1$. If wind is absent $(W=0)$ it can be seen that $\Delta P=+1$ reduces $\tau_{\mathrm{e}}$ by a factor of 5, whereas reversal of the density-forcing $(\Delta P=$ -1 ) reduces $\tau_{\mathrm{e}}$ by a factor of 2 only. In the former case the water mass renewal is more strongly enhanced, since the density-driven component of the circulation, which is most effective in the deep parts of the shelf, coincides with the tide-driven component. In the latter case, density-driven component of the circulation opposes the tide-driven component: the net effect is cyclonic circulation on the shallow shelf and anticyclonic circulation on the deeper shelf. Consequently, there is relatively effective flushing of the deep parts but trapping of material on the shallow shelf.

The addition of wind-forcing that leads to a pattern that coincides with the tide- and density-driven flow, favors water mass renewal. The curve for $\Delta P=+1$ behaves qualitatively similarly for positive winds as does the curve for the opposite density forcing for the opposite winds. Thus, in any climate where effects of winds and density coincide, the basin-mean water mass renewal changes little.

Differences become larger for winds opposing the density-driven circulation, however. For present-day

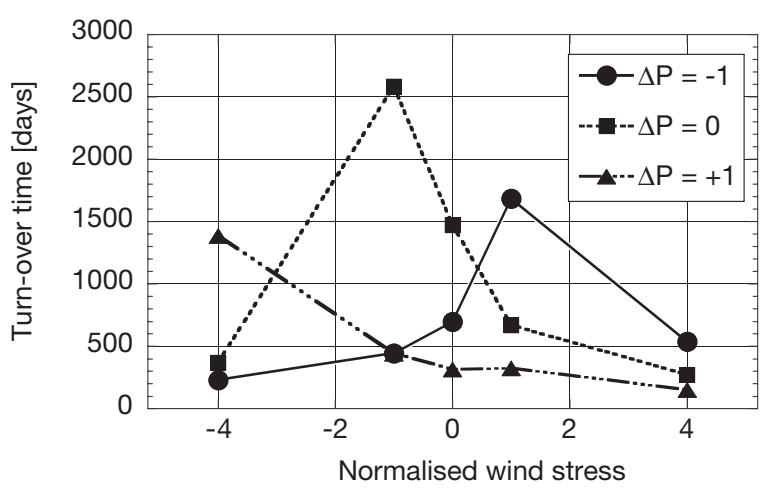

Fig. 5. Turnover time $\tau_{\mathrm{e}}$ (d) for the North Sea as a whole, computed with the tide-averaged dispersion model for 15 experiments 


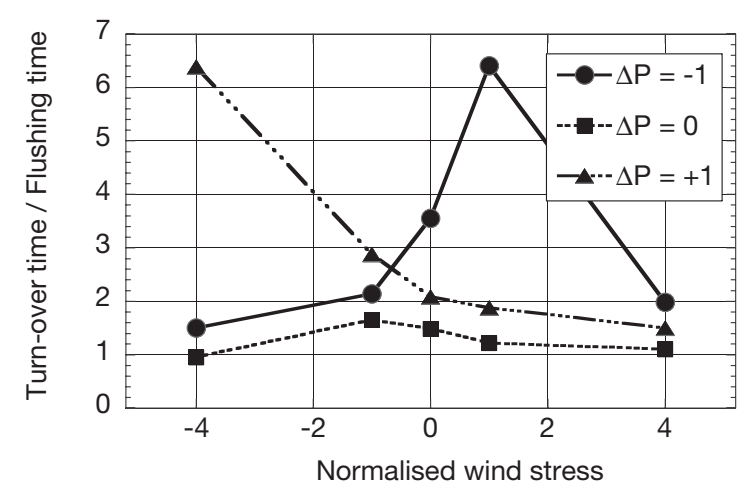

Fig. 6. Ratio of turnover time and flushing time $R_{\mathrm{ef}}=\tau_{\mathrm{e}} / \tau_{f}$ as computed from the tide-averaged dispersion model for 15 experiments

density-forcing $(\Delta P=+1)$, a change in the wind climatology (northeasterly winds, $W<0$ ) would partly reverse the residual circulation pattern: the circulation shows the occurrence of closed cells on the shelf because wind-forcing is most effective on the shallow parts, whereas density-forcing is most effective in the deep parts. As a consequence, $\tau_{\mathrm{e}}$ increases even for the strongest northeasterly winds.

For the extreme greenhouse climate scenario $(\Delta P=$ -1) on the other hand, the response for weak positive wind-forcing is already relatively strong (more than a doubling of $\tau_{\mathrm{e}}$ ) but, for further increase of the windforcing, $\tau_{\mathrm{e}}$ is strongly reduced: then winds and tides overcome density effects.

In Fig. 6, the ratio of turnover time and flushing time $R_{\mathrm{e} f}=\tau_{\mathrm{e}} / \tau_{f}$ is plotted. As mentioned above, the more $R_{\mathrm{e} f}$ deviates from unity, the stronger the retention of material in cell-like structures. Material can escape from these circulation cells by dispersion across streamlines only. For the cases in which density-forcing is absent, $R_{\mathrm{e} f}$ is relatively close to unity. For $\Delta P=+1$, however, wind-forcing opposing the tide- and density-driven pattern increases $R_{\text {ef }}$ significantly. The opposite happens for $\Delta P=-1$, although for increasing winds opposing the density-driven circulation, but coinciding with the tide-driven circulation, $R_{\text {ef }}$ decreases again.

\section{CONCLUSIONS}

Perhaps the experiments presented above may not seem very realistic. Important features such as the horizontal and vertical density distribution on the shelf have been neglected. These experiments aim mainly to provide better insight into the role of oceanic density-forcing on the shelf sea circulation and are not meant to be realistic 'forecasts'.
Several aspects of the residual circulation of the North Sea due to tides, winds, and density-forcing have been discussed. It has been found, as expected, that wind-driven circulation dominates over the tidedriven residual circulation. However, the effect of the ocean-density distribution is not negligible, although the oceanic gradient is weak when compared to local gradients on the shelf. Due to the typical shape of the North Sea basin, the density-driven slope current intrudes into the deeper northern North Sea. In the Norwegian Trench the density-driven circulation is strong enough to overcome opposing circulation patterns induced by weak winds. Strong wind-forcing, however, dominates over the density-driven circulation, even in the deepest parts.

With respect to the discussion by Rodhe (1998) on the role of wind and local buoyancy effects contributing to the circulation in the Norwegian Trench, it is interesting to remark that in the present-day setting the oceanic density-forcing is also responsible for a significant contribution to the barotropic residual circulation in the Trench and the Skagerrak. In addition, it has been found that the slope current affects the North Sea as a whole, which has not been clearly pointed out in earlier studies.

The dependence of the wind-driven component of residual circulation on wind stress is largely linear, except in localized areas where residual currents are so large that they influence the tidal rectification (mainly in the Norwegian Trench). However, the density-driven component of the residual circulation is not symmetrically dependent on the density-forcing; a positive density gradient, like the present-day situation, drives a stronger circulation than does an opposite density gradient of equal magnitude.

The basin-mean renewal of water mass in the North Sea, as quantified by the turn-over time, is strongly dependent on forcing. If wind effects overcome the other forcing then flushing is rapid. For weak winds, however, closed circulation patterns may develop on the shelf, especially when they oppose the density- and tide-driven circulation. This situation slows down water mass renewal considerably. To quantify the 'strength of retention', the ratio of turnover time and flushing time is used as an indication for the deviation of the circulation from a laminar pattern. Qualitative comparison of the ratio with flow structure shows good agreement.

In order to quantify the assertion that present-day forcing conditions are optimal for the flushing of the North Sea, as mentioned in the introduction, one should be careful in the use of time scales. From the previous results it can be concluded that if, for example, both wind and density-forcing are reversed, the basin-mean turnover of water mass seems almost as effective as it is now, but the strength of retention by 
closed circulation cells is about twice as strong. This result would imply larger spatial differences in water mass renewal on the shelf.

In conclusion, it should be remarked that in the experiments presented above it has been assumed that long-term dispersion can be reasonably well described by using stationary circulation, incorporating all the variability in the dispersion coefficient. This assumption might be questionable, certainly with reference to the non-linear dependence of the flushing characteristic on the wind forcing that has been found above. Therefore, further study will be carried out in which time-dependent wind stress will be applied to the circulation model. Furthermore, local density distributions on the shelf and baroclinic effects have not been taken into account. These effects are also to be considered in a future study, because they may counteract or strengthen the effects discussed here.

Acknowledgements. The authors acknowledge financial support from the Dutch National Institute for Coastal and Marine Management (RIKZ), grant no. RKZ-424. We also thank John de Ronde and Johan de Kok (RIKZ) for their interest and useful comments on this work and Edwin Spee (IMAU/RIKZ) for his valuable assistance with respect to the HAMSOM-code.

\section{LITERATURE CITED}

Backhaus JO (1983) A semi-implicit scheme for the shallow water equations for application to shelf sea modelling. Cont Shelf Res 2(4):243-254

Backhaus JO (1985) A three-dimensional model for the simulation of shelf sea dynamics. Dtsch Hydrogr Z 38:165-187

Backhaus JO (1989) The North Sea and the climate. Dana 8: 69-82

Backhaus JO (1996) Climate sensitivity of European marginal seas, derived from the interpretation of modelling studies. J Mar Systems 7:361-382

Bailly du Bois P, Guéguéniat P, Gandon R, Léon R, Baron Y (1993) Percentage contribution of inputs from the Atlantic, Irish Sea, English Channel and Baltic into the North Sea during 1988: A tracer-based evaluation using artificial radionuclides. Neth J Sea Res 31(1):1-17

Blaas M, Lam FPA, Gerkema T, De Swart HE (2000) On slope currents forced by density gradients and tidal rectification. In: T Yanagi (ed) Interactions between Estuaries, Coastal Seas and Shelf Seas. Terra Scientific, Tokyo, p 233-250

Bolin B, Rodhe H (1973) A note on the concepts of age distribution and transit time in natural reservoirs. Tellus 25(1): 58-62

Broecker WS (1991) The great ocean conveyor. Oceanogr 4(2):79-89

Broecker WS (1997) Thermohaline circulation, the Achilles heel of our climate system: will man-made $\mathrm{CO}_{2}$ upset the current balance? Science 278:1582-1588

Dansgaard W, Johnsen SJ, Clausen HB, Dahl-Jensen D, Gundestrup NS, Hammer CU, Hvidberg CS, Steffensen JP, Sveinbjörndottir AE, Jouzel J, Bond G (1993) Evidence for general instability of past climate from a 250 -kyr ice-core record. Nature 364:218-220

Duplessy JC, Labeyrie L, Juillet-Leclerc A, Maitre F, Duprat J,
Sarnthein M (1991) Surface salinity reconstruction of the North Atlantic Ocean during the last glacial maximum. Oceanol Acta 14(4):311-324

Furnes GK (1980) Wind effects in the North Sea. J Phys Oceanogr 10:978-984

Hass HC (1996) Northern Europe climate variations during late Holocene: evidence from marine Skagerrak. Palaeogeogr, Palaeoclimatol, Palaeoecol 123:121-145

Hellermann S, Rosenstein M (1983) Normal monthly wind stress over the world ocean with error estimates. J Phys Oceanogr 13:1093-1104

Huthnance JM (1986) The Rockall slope current and shelfedge processes. Proc R Soc Edinb Sect B (Biol) 88B:83-101

Kattenberg A, Giorgi F, Grassl H, Meehl GA, Mitchell JFB, Stouffer RJ, Tokioka T, Weaver AJ, Wigley T (1995) Climate models; projections of future climate. In: Houghton JT, Heira Filho LG, Callander BA, Harris N, Kattendberg A, Maskell K (eds) Climate Change 1995, the science of climate change; contribution of Working Group I to the 2nd Assessment Report of the IPCC. Cambridge University Press, Cambridge, p 285-357

Kautsky H (1973) The distribution of the radionuclide Caesium 137 as an indicator for North Sea watermass transport. Dtsch Hydrogr Z 26(6):241-246

Kerkhoven D (2000) The influence of the continental slope current on circulation and spreading characteristics in the North Sea. MSc thesis V-00-03, IMAU, Utrecht University

Levitus S, Boyer TP (1994) World ocean atlas 1994. NOAA Atlas NESDIS 3, Vol 3: Temperature, NODC, Silver Spring MD, USA

Levitus S, Burgett R, Boyer TP (1994) World ocean atlas 1994. NOAA Atlas NESDIS 3, Vol 4: Salinity, NODC, Silver Spring MD, USA

Manabe S, Stouffer RJ (1994) Multiple-century response of a coupled ocean-atmosphere model to an increase of atmospheric carbon dioxide. J Clim 7:5-23

Pingree RD, Le Cann B (1989) Celtic and Armorican slope and shelf residual currents. Prog Oceanogr 23:303-338

Pingree RD, Sinha B, Griffiths CR (1999) Seasonality of the European slope current (Goban Spur) and ocean margin exchange. Cont Shelf Res 19:929-975

Pohlmann T, Puls W (1994) Currents and transports in water. In: J Sündermann (ed) Circulation and contaminant fluxes in the North Sea. Springer, Berlin, p 345-402

Prandle D (1984) A modelling study of the mixing of ${ }^{137} \mathrm{Cs}$ in the seas of the European continental shelf. Philos Trans R Soc Lond A (Math Phys Sci) A310:407-436

Rodhe J (1998) The Baltic and North Seas: a process-oriented review of the physical oceanography. Coastal Segment $(20$, S). In: AR Robinson, Brink KH (eds) The sea, vol 11, Wiley, New York, p 699-732

Schiller A, Mikolajewicz U, Voss R (1997) The stability of the North Atlantic thermohaline circulation in a coupled ocean-atmosphere general circulation model. Clim Dyn 13:325-347

Schmittner A, Stocker TF (1999) The stability of the themohaline circulation in global warming experiments. J Clim 12: $1117-1133$

Stocker TF, Mysak LA (1992) Climatic fluctuations on the century time scale: a review of high-resolution proxy data and possible mechanisms. Clim Change 20:227-250

Sündermann J (ed) (1994) Circulation and contaminant fluxes in the North Sea. Springer, Berlin

Zimmerman JTF (1976) Mixing and flushing of tidal embayments in the Western Dutch Wadden Sea part I: distribution of salinity and calculation of mixing time scales. Neth J Sea Res 10(2):149-191 